\title{
Levantamento etnobotânico de plantas medicinais em área de Caatinga na comunidade do Sítio Nazaré, município de Milagres, Ceará, Brasil
}

SILVA,C.G. ${ }^{*} ;$ MARINHO,M.G.V.2; LUCENA,M.F.A.;; COSTA,J.G.M. ${ }^{4}$

Universidade Federal de Campina Grande, Pós-Graduação em Ciências Florestais, Unidade Acadêmica de Engenharia Florestal, Avenida Universitária, s/n, Bairro Santa Cecília, CEP 58700-970, Patos-Brasil *cleomariasilva@yahoo.com.br, 2Universidade Federal de Campina Grande, Pós-Graduação em Ciências Florestais, Unidade Acadêmica de Ciências Biológicas, Avenida Universitária, s/n, Bairro Santa Cecília, CEP 58700-970, Patos-Brasil, 3Universidade Federal de Campina Grande, Unidade Acadêmica de Ciências Biológicas, Herbário CSTR, Avenida Universitária, s/n, Bairro Santa Cecília, CEP 58700-970, Patos-Brasil, 4Universidade Regional do Cariri, Laboratório de Pesquisa de Produtos Naturais, Rua Cel. Antônio Luiz, 1161, Bairro Pimenta, CEP 63100-000, Crato-Brasil

RESUMO O presente trabalho teve como objetivo realizar um levantamento das plantas medicinais nativas no bioma Caatinga na comunidade do Sítio Nazaré, no município de Milagres, Ceará. Foram utilizadas entrevistas semiestruturadas com 100 informantes entre 25 a 85 anos registrando informações de 62 espécies medicinais sobre o uso, parte utilizada, indicação terapêutica, e formas de preparo dos remédios caseiros, além de coleta do material botânico e produção de exsicatas. As famílias com maior representatividade na pesquisa foram Fabaceae (16 spp.), Euphorbiaceae (7 spp.), Cucurbitaceae e Malvaceae (3 spp.), e as demais com duas ou uma espécie cada. Nas preparações dos remédios caseiros verificou-se que todas as partes da planta são utilizadas, predominando as raízes $(33,77 \%)$ e as cascas $(29,87 \%)$. Observaram-se várias formas de preparo, sendo o chá a mais indicada $(49,21 \%)$, seguida do lambedor $(40,69 \%)$. Os dados encontrados revelaram que o conhecimento popular sobre as plantas medicinais é de extrema importância para o controle das afecções e contribui para a realização de estudos etnofarmacológicos.

Palavras-chave: Caatinga, etnobotânica, plantas medicinais, Ceará.

ABSTRACT: Ethnobotanical survey of medicinal plants in the Caatinga area in the community of Sitio Nazaré, Milagres, Ceará, Brazil. The present study aimed to survey the native medicinal plants in the biome Caatinga in the community of Sítio Nazaré from Milagres, in Ceará, Brazil. Semi-structured interviews with 100 persons, from 25 to 85 years old, were recorded. Sixty-two species were pointed for medical information on use, used plant part, therapeutic indication and methods of preparation of home remedies. We also prepared the collection of botanical material and production of exsiccates. The most representative families reported in this study were: Fabaceae (15 spp.), Euphorbiaceae (7 spp.), Cucurbitaceae and Malvaceae ( $3 \mathrm{spp}$.). On the preparation of remedies, we found that all parts of the plants were used, predominantly the roots $(33.77 \%)$ and the barks $(29.87 \%)$. The most common way of preparation observed was tea $(49.21 \%)$, followed by syrup $(40.69 \%)$. These collected data revealed that popular knowledge on medicinal Caatinga plants were important for disease control in the local population and it has contributed to other ethnopharmacology studies.

Key words: Caatinga, ethnobotanical, medicinal plants, Ceará.

\section{INTRODUÇÃO}

Toda sociedade humana acumula um acervo de informações que a possibilita interagir e prover suas necessidades de sobrevivência. $O$ ser humano foi e, ainda é, importante agente de mudanças vegetacionais e de evolução vegetal, porque sempre foi dependente do meio botânico para a sobrevivência, manipulando-o não somente para suprir as necessidades mais urgentes, mas também na magia e medicina, no uso empírico ou simbólico, nos ritos gerenciadores da vida e mantenedores da ordem social (Albuquerque, 2005). Reconhecer a importância das relações entre o

Recebido para publicação em 04/06/2012

Aceito para publicação em 24/06/2014

10.1590/1983-084X/12_055

Rev. Bras. Pl. Med., Campinas, v.17, n.1, p.133-142, 2015. 
homem e a natureza significa um avanço cognitivo (Santos et al., 2008).

Muitas comunidades rurais do nordeste estão inseridas em áreas de vegetação de caatinga, onde tiram seu sustento, através da agricultura, assim como, de produtos não madeireiros, como ervas medicinais, óleos, sementes, frutos. As plantas medicinais acabam sendo a única alternativa dessas comunidades para combater suas enfermidades, sendo o único recurso disponível. Para Pilla et al. (2006), à medida que a relação com a terra passa por uma modernização e o contato com centros urbanos se intensifica, a rede de transmissão do conhecimento sobre plantas medicinais pode sofrer alterações, sendo necessário com urgência fazer o resgate deste conhecimento e das técnicas terapêuticas, como uma maneira de deixar registrado este modo de aprendizado informal.

A partir de levantamentos em determinadas comunidades locais pode-se averiguar as potencialidades dos recursos vegetacionais, desde medicinais, alimentares, madeireiros, forrageiros, assim como, as formas de uso repassado para futuras gerações pelos moradores.

Através disso, o estudo da etnobotânica busca não só o registro do uso dos recursos vegetais presentes em determinada área, mas as formas de manejo como são empregadas por comunidades tradicionais. O conhecimento repassado de geração a geração nas comunidades tradicionais, sobre os recursos terapêuticos das plantas encontradas em seu ambiente natural pode ser um instrumento importante, como por exemplo, para indústria farmacêutica na elaboração de novos medicamentos. A etnobotânica é citada na literatura como sendo um dos caminhos alternativos que mais evoluiu nos últimos anos para a descoberta de produtos naturais bioativos (Maciel et al., 2002).

O objetivo do presente trabalho foi realizar o estudo etnobotânico de espécies vegetais nativas utilizadas como plantas medicinais por moradores locais da comunidade do Sítio Nazaré, município de Milagres-CE. Para isso foram investigados: as partes das plantas utilizadas, as principais doenças combatidas, a forma de preparo e uso dos medicamentos e número indicado de plantas por informantes.

\section{MATERIAL E MÉTODOS}

O Sítio Nazaré está situado a $5 \mathrm{~km}$ do município de Milagres, as margens da BR 116, próxima a Reserva Lega da Fazenda Nazaré, onde esta foi dividida em duas áreas: A1 (07017'52"S e

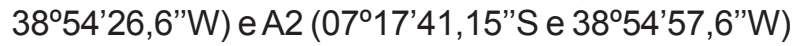
(Figura 1). O município de Milagres está localizado na mesorregião do Sul cearense e na microrregião de Brejo Santo, com área de $577 \mathrm{Km}^{2}, 499 \mathrm{~km}$ da capital Fortaleza (IBGE, 2010).

Possui um clima semiárido, conforme a classificação de Köppen é do tipo BSh', tropical quente, temperatura média anual de $26^{\circ} \mathrm{C}$. A precipitação média anual é de $939 \mathrm{~mm}$, com período chuvoso de fevereiro a abril. O relevo inclui a Chapada do Araripe e Depressão sertaneja. Os solos em sua maioria são litólicos, podzólico vermelho-amarelo e vertissolo (IPECE, 2009).

A coleta de dados foi feita mensalmente na comunidade rural do Sítio Nazaré, no período de janeiro a dezembro de 2011, na estação chuvosa e seca. Utilizaram-se observação participante, entrevistas semiestruturadas e estruturadas (Albuquerque \& Lucena, 2004), buscando obter informações sobre o potencial medicinal e características botânicas das plantas utilizadas.

Foram entrevistados 100 (cem) moradores entre 25 a 85 anos, sendo considerados especialistas locais (raizeiros, mateiros, agricultores, rezadeiras, donas-de-casa), onde se utilizou como técnica de amostragem a metodologia proposta por Bailey (1994), chamada "bola de neve" (snow ball), onde o primeiro especialista entrevistado indica o próximo, e assim por diante, até chegar o final do estudo, onde todos especialistas da comunidades estejam entrevistados. O grau de escolaridade da maioria dos entrevistados foi o $5^{\circ}$ ano do Ensino Fundamental, onde a vida cotidiana está voltada à agricultura familiar. Residem em casas de alvenaria, sem saneamento básico, apesar de possuir no local, um Posto de Saúde, onde são realizadas as consultas uma vez por semana.

A coleta do material vegetativo fértil (com flor, fruto) foi realizada na Reserva Legal, que em seguida, foram feitas exsicatas e duplicatas, realizando todo processo de herborização proposto por Bridson \& Forman (1998), onde foram depositadas no Herbário CSTR, da Universidade Federal de Campina Grande, sendo incorporadas à sua coleção. Análises morfológicas para as identificações, descrições das espécies foram realizadas com auxílio de chaves analíticas, diagnoses encontradas na bibliografia, e os nomes científicos das espécies estão de acordo com o site Forzza et al.(2012).

A frequência relativa das plantas medicinais foi calculada no Programa Excel, conforme Martins (1979), Castro (1987), Rodal et al (1992). Apenas as plantas que apresentaram frequência de citação $\geq 5 \%$ foram consideradas para fins de discussão.

Um checklist foi elaborado contendo nomes científicos e populares, bem como finalidades terapêuticas, formas de uso, parte(s) utilizada(s) e indicação das espécies mencionadas pelos informantes locais. 


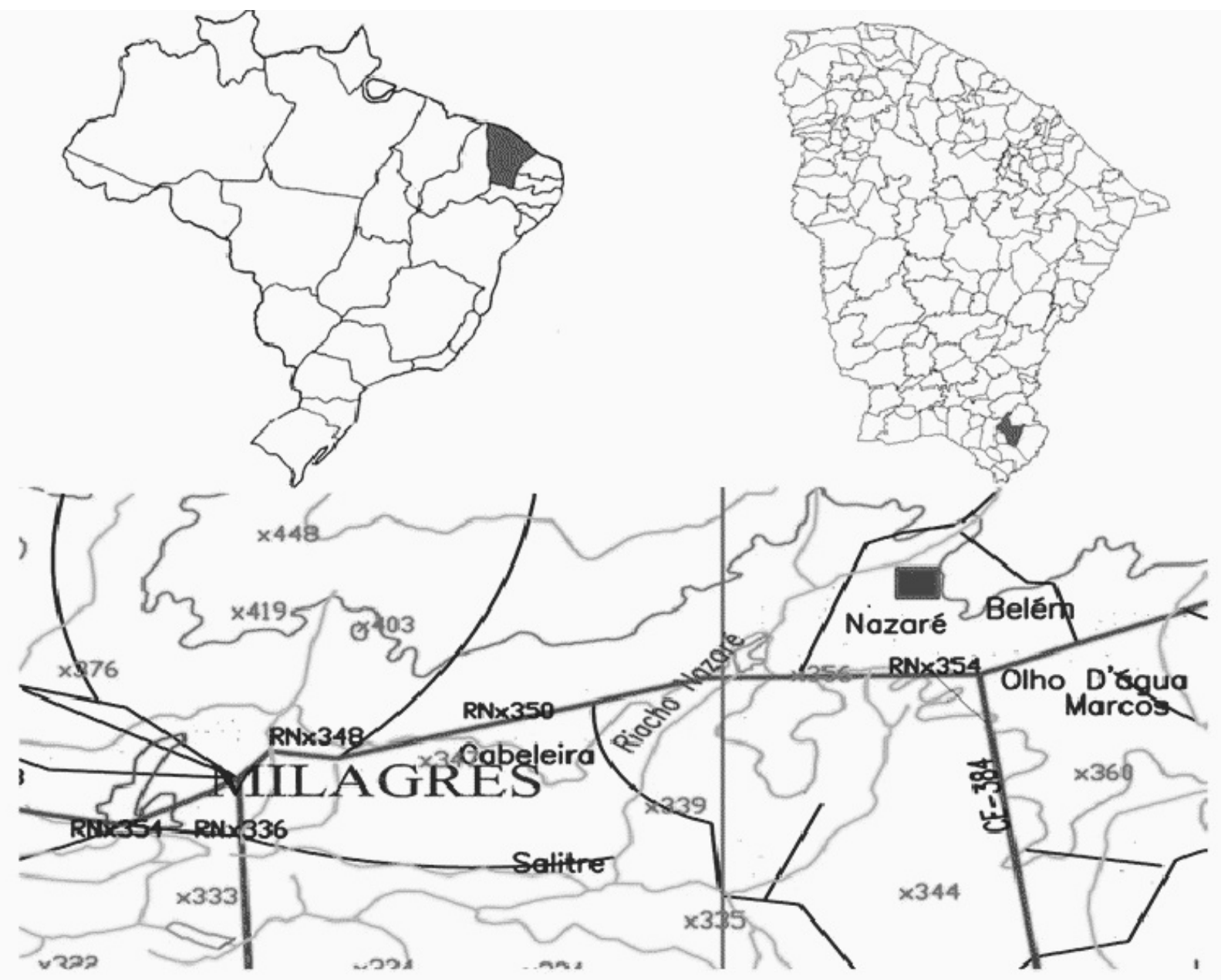

FIGURA 1. Localização da área de estudo, Sítio Nazaré, município de Milagres, CE:

\section{RESULTADO E DISCUSSÃO}

Foram citadas 62 espécies, 31 famílias e 53 gêneros, sendo 2 espécies identificadas apenas a nível de gênero (Sapium sp.; Ocimum sp.) (Tabela 1). As famílias com maior representatividade foram Fabaceae (16 spp.), Euphorbiaceae (7 spp.), Cucurbitaceae e Malvaceae (3 spp.) e, as demais com duas ou uma espécie cada. Muitos trabalhos realizados no bioma Caatinga como o de Roque et al. (2010), Albuquerque \& Andrade (2002), Florentino et al. (2007) reforçam a existência de espécies medicinais nativas do bioma na região nordeste.

Nesta pesquisa foram dada ênfase apenas as espécies medicinais nativas e sendo consideradas para fins de discussão, as espécies com frequência de citação $\geq 5 \%$, por ter sido citada diversas vezes entre os entrevistados. Para comprovar o nome das espécies utilizou-se, para esta finalidade bibliografia especializada.

Dentre as 62 espécies medicinais indicadas durante as entrevistas, $H$. courbaril $(9,5 \%), A$. cearensis $(9,2 \%)$, M. urundeuva $(8,4 \%)$ e $C$. grewioides $(8,3 \%)$ foram as mais citadas pelos informantes da comunidade do Sítio Nazaré, seguidas das demais que tem suas particularidades, na cura de várias enfermidades, como gripes, resfriados, tosse, e sendo entre muitas das plantas medicinais local, repassadas pelos povos mais antigos como "plantas milagrosas" (Tabela 2).

No Sítio Nazaré a idade dos informantes foi entre 25 a 85 anos, onde a faixa etária entre 36 a 45 anos, entre ambos os sexos, obteve uma maior porcentagem, correspondendo a $28 \%$. O maior número de entrevistados pertence ao sexo feminino (67\%). A presença da mulher se destacou, devido ao fato de passar mais tempo em casa e ser a responsável por cuidar do ambiente familiar, enquanto o homem dedica suas atividades fora de sua residência. Estudos realizados por Marinho et al. (2011), no município São José de EspinharasPB, dos informantes entre 30 a 60 anos, (70\%) foi do sexo feminino, assim como, Silva et al. (2012), no município de São João da Ponte-MG confirma que $77 \%$ dos entrevistados entre 28 a 78 anos, pertenciam ao sexo feminino, sendo verificados os dados percentuais na pesquisa em estudo.

O tempo de residência dos informantes

Rev. Bras. PI. Med., Campinas, v.17, n.1, p.133-142, 2015. 
TABELA 1. Espécies medicinais utilizadas pela comunidade do Sítio Nazaré, município de Milagres-CE. Convenções: Voucher (Herbário CSTR); NI/PI = Número de Indicações por Plantas pelos Informantes; ${ }^{*}$ Plantas consideradas para fins de discussão.

\begin{tabular}{|c|c|c|c|c|c|c|c|}
\hline Voucher & Família/Nome Científico & $\begin{array}{c}\text { Nome } \\
\text { popular }\end{array}$ & $\begin{array}{l}\text { Parte } \\
\text { usada }\end{array}$ & Forma de uso & Indicação terapêutica & $\mathrm{NI} / \mathrm{PI}$ & $\begin{array}{c}\text { Frequência } \\
\text { Relativa } \\
(\geq 5 \%)^{*}\end{array}$ \\
\hline & ANACARDIACEAE & & & & & & \\
\hline 3053 & $\begin{array}{c}\text { Anacardium occidentale } \\
\text { L. }\end{array}$ & caju & $\begin{array}{l}\text { casca, flor e } \\
\text { entrecasca }\end{array}$ & $\begin{array}{c}\text { chá, maceração, } \\
\text { decocção }\end{array}$ & $\begin{array}{l}\text { anti-inflamatório, } \\
\text { adstringente }\end{array}$ & 15 & $2,3 \%$ \\
\hline 3052 & $\begin{array}{l}\text { Myracrodruon urundeuva } \\
\text { Allemão }\end{array}$ & $\begin{array}{l}\text { aroeira } \\
\text { mansa }\end{array}$ & casca & $\begin{array}{l}\text { chá, maceração, } \\
\text { banho de assento }\end{array}$ & $\begin{array}{l}\text { anti-inflamatório, } \\
\text { bronquite, inflamações } \\
\text { do útero }\end{array}$ & 56 & $8,4 \%$ \\
\hline 3051 & $\begin{array}{l}\text { APOCYNACEAE } \\
\text { Calotropis procera } \\
\text { (Aiton) W.T. Aiton } \\
\text { ARECACEAE }\end{array}$ & $\begin{array}{l}\text { algodão-de- } \\
\text { seda }\end{array}$ & látex & látex puro & verruga & 1 & - \\
\hline 3050 & $\begin{array}{c}\text { Syagrus comosa (Mart.) } \\
\text { Mart. } \\
\text { ASTERACEAE }\end{array}$ & catolé & raiz e fruto & água do fruto & $\begin{array}{l}\text { olho inflamado, pedra } \\
\text { nos rins }\end{array}$ & 8 & $1,2 \%$ \\
\hline 2995 & $\begin{array}{l}\text { Acanthospermum } \\
\text { hispidum DC. }\end{array}$ & $\begin{array}{l}\text { espinho de } \\
\text { cigano }\end{array}$ & raiz & chá, lambedor & gripe, béquico, febrífuga & 17 & $2,6 \%$ \\
\hline 3049 & Ageratum conyzoides L. & mentrasto & $\begin{array}{l}\text { toda a } \\
\text { planta }\end{array}$ & chá, lambedor & emenagogo, depurativo & 4 & - \\
\hline 3067 & $\begin{array}{c}\text { BIGNONIACEAE } \\
\text { Handroanthus } \\
\text { impetiginosus Mattos }\end{array}$ & ipê rosa & casca & $\begin{array}{l}\text { infusão, lambedor, } \\
\text { xarope }\end{array}$ & $\begin{array}{l}\text { anti-inflamatório, anti- } \\
\text { cancerígeno e anti- } \\
\text { cardíaco }\end{array}$ & 7 & $1,0 \%$ \\
\hline \multirow[t]{2}{*}{3062} & $\begin{array}{c}\text { BORAGINACEAE } \\
\text { Heliotropium elongatum } \\
\text { (Lehm.) I. M. Johnst. }\end{array}$ & $\begin{array}{l}\text { crista de } \\
\text { galo }\end{array}$ & raiz & chá, lambedor & $\begin{array}{l}\text { gripe, béquico, anti- } \\
\text { inflamatório }\end{array}$ & 10 & $1,5 \%$ \\
\hline & CACTACEAE & & & & & & \\
\hline 2948 & $\begin{array}{c}\text { Harrisia adscendens } \\
\text { (Gürke) Britton \& Rose }\end{array}$ & $\begin{array}{l}\text { rabo de } \\
\text { raposa }\end{array}$ & raiz e folha & $\begin{array}{l}\text { chá, infusão, } \\
\text { lambedor } \\
\text { in natura }\end{array}$ & $\begin{array}{l}\text { anti-inflamatório, } \\
\text { doenças da próstata, } \\
\text { cardíacas e renais, } \\
\text { gripe, béquico } \\
\text { retirada de espinhos na } \\
\text { epiderme }\end{array}$ & 24 & $3,6 \%$ \\
\hline 3048 & $\begin{array}{l}\text { CAPPARACEAE } \\
\text { Tarenaya spionosa } \\
\text { (Jacq.) Raf. }\end{array}$ & mussambê & $\begin{array}{l}\text { raiz, flor, } \\
\text { planta } \\
\text { inteira }\end{array}$ & $\begin{array}{l}\text { chá, lambedor, } \\
\text { xarope }\end{array}$ & $\begin{array}{l}\text { gripe, bequíco, } \\
\text { inflamações }\end{array}$ & 10 & $1,5 \%$ \\
\hline 3058 & $\begin{array}{l}\text { CONVOLVULACEAE } \\
\text { Operculina macrocarpa } \\
\text { (L.) Urb. }\end{array}$ & $\begin{array}{l}\text { batata-de- } \\
\text { purga }\end{array}$ & tubérculo & infusão, xarope & $\begin{array}{c}\text { gripe, carminativa, } \\
\text { vermífugo, } \\
\text { antiasmática, } \\
\text { hemostático }\end{array}$ & 1 & - \\
\hline 3047 & $\begin{array}{l}\text { CUCURBITACEAE } \\
\text { Luffa operculata (L.) } \\
\text { Cogn. }\end{array}$ & cabacinha & fruto & infusão, decocção, & sinusite, febre & 3 & - \\
\hline
\end{tabular}


TABELA 1. Espécies medicinais utilizadas pela comunidade do Sítio Nazaré, município de Milagres-CE. Convenções: Voucher (Herbário CSTR); NI/PI = Número de Indicações por Plantas pelos Informantes; ${ }^{*}$ Plantas consideradas para fins de discussão.

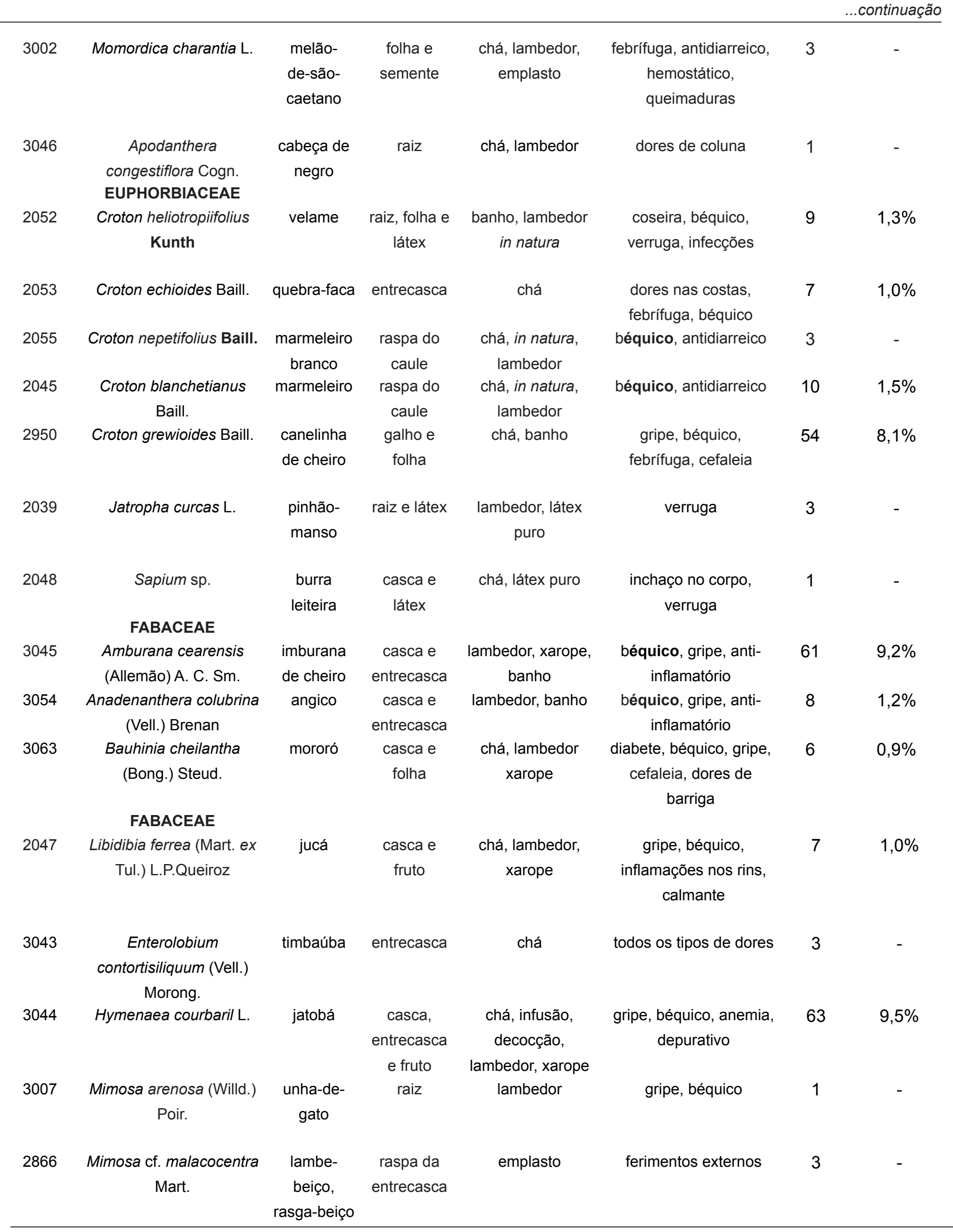


TABELA 1. Espécies medicinais utilizadas pela comunidade do Sítio Nazaré, município de Milagres-CE. Convenções: Voucher (Herbário CSTR); NI/PI = Número de Indicações por Plantas pelos Informantes; ${ }^{*}$ Plantas consideradas para fins de discussão.

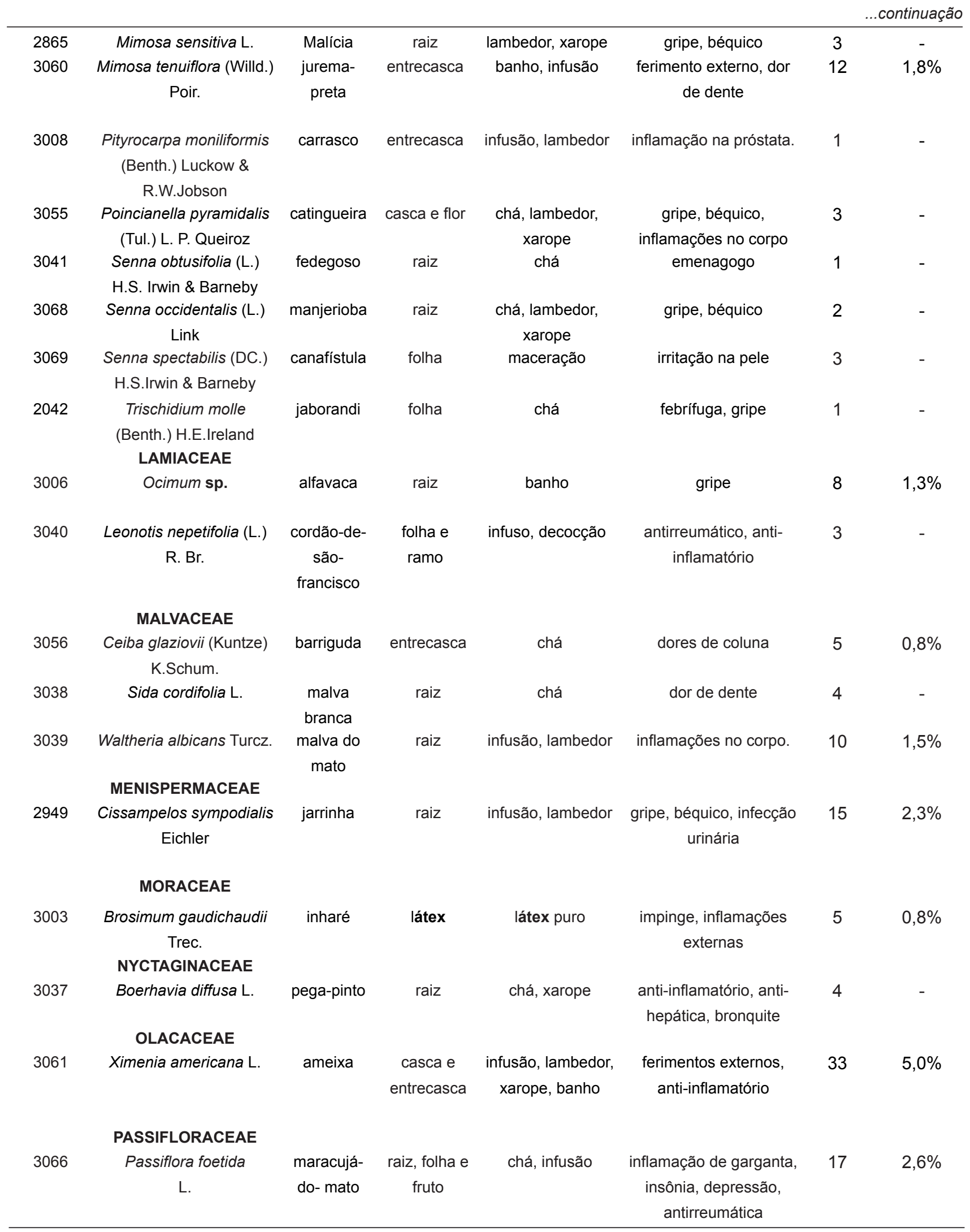


TABELA 1. Espécies medicinais utilizadas pela comunidade do Sítio Nazaré, município de Milagres-CE. Convenções: Voucher (Herbário CSTR); NI/PI = Número de Indicações por Plantas pelos Informantes; ${ }^{*}$ Plantas consideradas para fins de discussão.

...continuação

\begin{tabular}{|c|c|c|c|c|c|c|c|}
\hline 3057 & $\begin{array}{l}\text { PHYLLANTHACEAE } \\
\text { Phyllanthus niruri L. }\end{array}$ & $\begin{array}{l}\text { quebra- } \\
\text { pedra }\end{array}$ & raiz e folha & $\begin{array}{l}\text { chá, lambedor, } \\
\text { xarope }\end{array}$ & pedras nos rins, fígado & 13 & $2,0 \%$ \\
\hline 3036 & $\begin{array}{l}\text { PHYTOLACCACEAE } \\
\text { Petiveria alliacea L. }\end{array}$ & tipí & raiz e folha & $\begin{array}{l}\text { chá, lambedor, } \\
\text { banho }\end{array}$ & $\begin{array}{l}\text { antirreumática, dor de } \\
\text { coluna }\end{array}$ & 9 & $1,4 \%$ \\
\hline 3035 & $\begin{array}{l}\text { PLANTAGINACEAE } \\
\text { Scoparia dulcis L. }\end{array}$ & vassourinha & toda a planta & chá, xarope & $\begin{array}{c}\text { bronquite, infecção } \\
\text { urinária, emenagogo, } \\
\text { infecções do útero, anti- } \\
\text { inflamatório }\end{array}$ & 14 & $2,1 \%$ \\
\hline 3065 & $\begin{array}{c}\text { RHAMNACEAE } \\
\text { Ziziphus joazeiro Mart. }\end{array}$ & juazeiro & $\begin{array}{l}\text { entrecasca, } \\
\text { folha e fruto }\end{array}$ & $\begin{array}{c}\text { chá, } \\
\text { infusão,decocção }\end{array}$ & $\begin{array}{c}\text { anemia, dores de } \\
\text { barriga, inflamações }\end{array}$ & 22 & $3,3 \%$ \\
\hline & RUBIACEAE & & & & & & \\
\hline 3034 & $\begin{array}{l}\text { Coutarea hexandra } \\
\text { (Jacq). K. Schum. }\end{array}$ & quina-quina & entrecasca & $\begin{array}{l}\text { chá, infusão, } \\
\text { decocção }\end{array}$ & $\begin{array}{l}\text { gripe, tosse, anti- } \\
\text { inflamatório, sinusite }\end{array}$ & 24 & $3,6 \%$ \\
\hline 3033 & $\begin{array}{l}\text { Genipa americana L. } \\
\text { SAPINDACEAE }\end{array}$ & genipapinho & entrecasca & emplasto & luxação e hematomas & 12 & $1,8 \%$ \\
\hline 2046 & $\begin{array}{l}\text { Cardiospermum } \\
\text { corindum L. } \\
\text { SAPOTACEAE }\end{array}$ & $\begin{array}{l}\text { cipó-de- } \\
\text { vaqueiro }\end{array}$ & raiz & $\begin{array}{l}\text { chá, lambedor, } \\
\text { xarope }\end{array}$ & $\begin{array}{c}\text { gripe, béquico, } \\
\text { inflamações no corpo }\end{array}$ & 16 & $2,4 \%$ \\
\hline 2947 & $\begin{array}{l}\text { Sideroxylon obtusifolium } \\
\text { (Roem. \& Schult.) T. D. } \\
\text { Penn. } \\
\text { SELAGINELACEAE }\end{array}$ & quixaba & $\begin{array}{c}\text { casca e } \\
\text { entrecasca }\end{array}$ & $\begin{array}{l}\text { chá, infusão e } \\
\text { lambedor }\end{array}$ & $\begin{array}{c}\text { gripe, béquico, } \\
\text { inflamações no corpo }\end{array}$ & 23 & $3,4 \%$ \\
\hline 3032 & $\begin{array}{c}\text { Selaginella convuluta } \\
\text { Spring. } \\
\text { SOLANACEAE }\end{array}$ & jericó & raiz & chá, lambedor & gripe, dores de barriga & 5 & $0,8 \%$ \\
\hline 3031 & $\begin{array}{l}\text { Solanum agrarium } \\
\text { Sendtn. } \\
\text { TURNERACEAE }\end{array}$ & gogoia & raiz & chá, lambedor & $\begin{array}{c}\text { infecção urinária, } \\
\text { hemorroidas, vermífugo }\end{array}$ & 12 & $1,8 \%$ \\
\hline 3004 & Turnera subulata Sm. & chanana & raiz e folha & $\begin{array}{l}\text { chá, infusão, } \\
\text { xarope, emplasto }\end{array}$ & $\begin{array}{c}\text { infecção urinária, } \\
\text { doença da próstata, anti- } \\
\text { inflamatório }\end{array}$ & 15 & $2,3 \%$ \\
\hline & VERBENACEAE & & & & & & \\
\hline $\begin{array}{l}3011 \\
3010\end{array}$ & $\begin{array}{c}\text { Lantana camara L. } \\
\text { Lippia microphylla Cham. }\end{array}$ & $\begin{array}{l}\text { chumbinho } \\
\text { alecrim de } \\
\text { tabuleiro }\end{array}$ & $\begin{array}{c}\text { raiz } \\
\text { planta inteira }\end{array}$ & $\begin{array}{l}\text { chá, lambedor } \\
\text { chá, lambedor }\end{array}$ & $\begin{array}{c}\text { béquico, gripe } \\
\text { gripe, cefaleia, sinusite, } \\
\text { béquico }\end{array}$ & $\begin{array}{c}1 \\
12\end{array}$ & - \\
\hline 3064 & $\begin{array}{c}\text { VIOLACEAE } \\
\text { Hybanthus calceolaria } \\
\text { (L.) Oken }\end{array}$ & papaconha & raiz & chá, lambedor & $\begin{array}{c}\text { falta de apetite, dentição } \\
\text { de criança }\end{array}$ & 14 & $2,1 \%$ \\
\hline
\end{tabular}

numa escala de 2 até mais de 50 anos, 30\% (30 a 50 anos) moram no local, onde os demais foram embora para a cidade ou se destinaram para outros Estados, como por exemplo, o Sudeste do Brasil, para trabalharem em indústrias, na construção civil, grandes plantações agrícolas, em busca de melhores condições de vida.

A maioria dos entrevistados afirmou que obteve o conhecimento adquirido sobre o uso das plantas medicinais através dos pais 
TABELA2. Espécies consideradas pelos informantes significativas para cura de enfermidades. NI/ $\mathrm{PI}$ : Número de Indicações por Plantas pelos Informantes; FR: Frequência Relativa ( $\geq 5 \%$ ).

\begin{tabular}{lll}
\hline Espécies & NI/PI & FR (\%) \\
\hline H. courbaril (jatobá) & 63 & 9,5 \\
A. cearensis (imburana de cheiro) & 61 & 9,2 \\
M. urundeuva (aroeira mansa) & 56 & 8,4 \\
C. grewioides (canelinha de cheiro) & 54 & 8,1 \\
X. americana (ameixa) & 33 & 5 \\
C. jamacaru (mandacaru) & 24 & 3,6 \\
C. hexandra (quina-quina) & 24 & 3,7 \\
S. obtusifolium (quixaba) & 23 & 3,4 \\
Z. joazeiro (juazeiro) & 22 & 3,3 \\
A. hispidum (espinho de cigano) & 17 & 2,6 \\
P. foetida (maracujá do mato) & 17 & 2,5 \\
C. corindum (cipó-de-vaqueiro) & 16 & 2,4 \\
A. occidentale (caju) & 15 & 2,3 \\
T. subulata (chanana) & 15 & 1,8 \\
C. sympodialis (jarrinha) & 15 & 2,3 \\
H. calceolaria (papaconha) & 14 & 2,3 \\
S. dulcis (vassourinha) & 14 & 2,2 \\
P. niruri (quebra-pedra) & 13 & 2,0 \\
L. microphylla (alecrim de tabuleiro) & 12 & 1,8 \\
G. americana (genipapinho) & 12 & 1,8 \\
M. tenuiflora (jurema preta) & 12 & 1,8 \\
\hline
\end{tabular}

(74\%), verificando que os demais relataram ter informações sobre as plantas medicinais com tios, vizinhos e até mesmo, com os filhos mais jovens (Figura 2). Marinho (2006) verificou no município de São José de Espinharas - PB, que $85 \%$ dos entrevistados adquiriram o aprendizado sobre as plantas medicinais com os pais.

Para obter um estudo comparativo sobre as partes e formas de uso das plantas medicinais, a opinião entre homens e mulheres foi dividida, como forma de investigar o saber adquirido por estes gêneros ao longo de suas gerações. Para preparação dos remédios caseiros, as partes utilizadas foram raízes, cascas do caule, folhas, flores, frutos e sementes, onde se verificaram que $(33,77 \%)$ dos homens utilizavam às raízes e $(29,51 \%)$ das mulheres as cascas do caule, embora as folhas sejam procuradas para cura das enfermidades dos homens $(28,96 \%)$ e mulheres $(32,47 \%)$ (Figura 3). Oliveira et al. (2005) relatam para o município de Caruaru-PE, que as plantas medicinais localmente disponíveis fornecem estruturas perenes (cascas, entrecascas e raízes) para uso medicinal, assim como, as não perenes (folhas, flores e frutos), onde o uso medicinal das espécies em questão, não significam sua utilização efetiva, mas o seu conhecimento sobre o uso de forma empírica.

Diversas formas de preparo dos remédios caseiros foram indicadas por homens e mulheres, como lambedor, xarope, chás por decocção e infusão, macerado em água, álcool, cachaça e vinho, banho de assento, compressas e outros. Verificouse entre as mulheres $(43,45 \%)$ e os homens $(49,21 \%)$, que o chá foi à forma de preparo mais citada, seguido de lambedor $(40,69 \%)$ e $(33,33 \%)$, respectivamente para curar as enfermidades (Figura 4). Trabalhos como o de Marinho et al. (2011), Baldauf et al. (2009), reforçam esta prática.

A troca de informações, desde os mais velhos aos mais jovens, é recíproca e dinâmica, em que a relação homem-planta medicinal se completa e mantém vivo o conhecimento. Vários dos

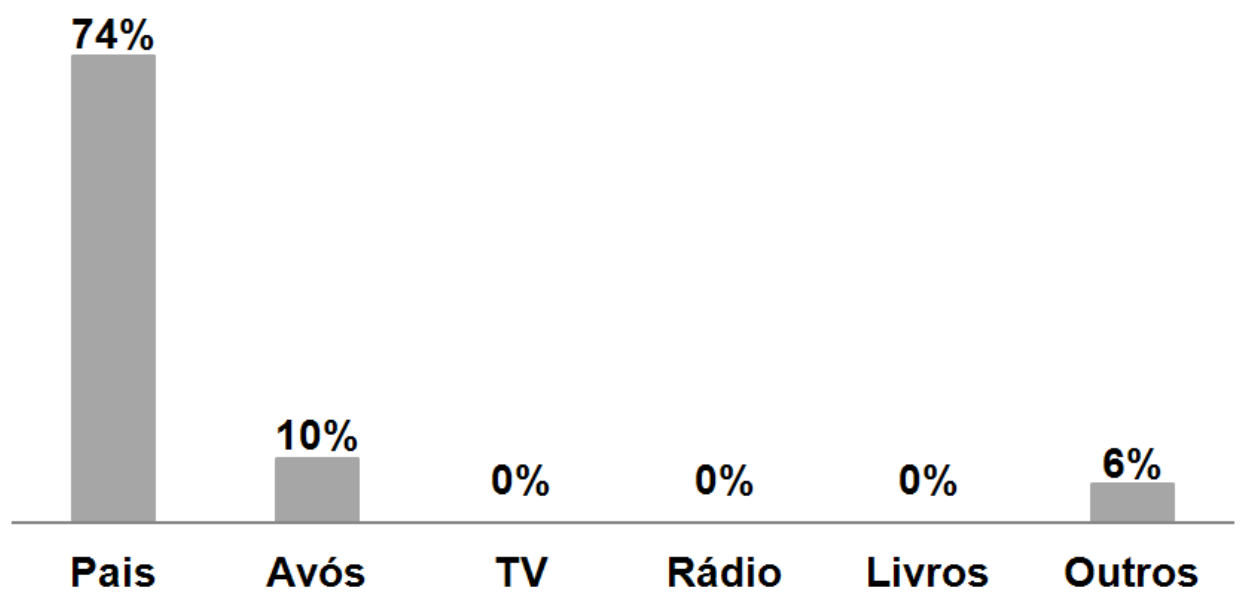

FIGURA 2. Herança de conhecimento das espécies de plantas medicinais dos moradores do Sítio Nazaré, município de Milagres-CE. 


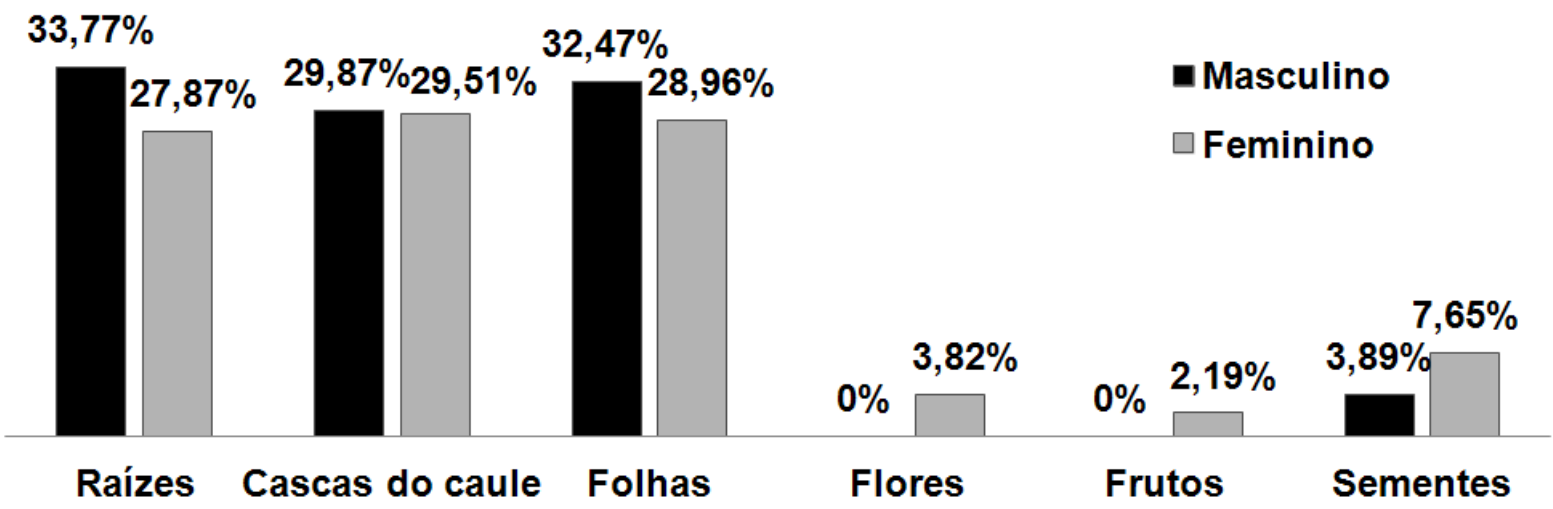

FIGURA 3. Partes utilizadas das plantas medicinais pela comunidade do Sítio Nazaré, município de Milagres-CE.

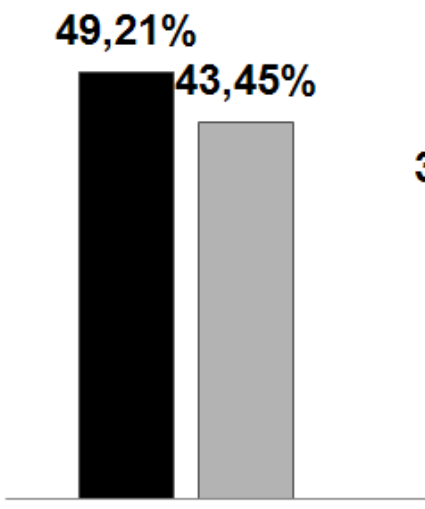

Chá

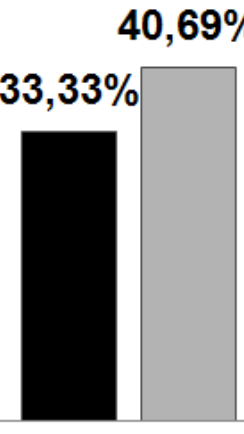

Lambedor
- Masculino

$\square$ Feminino

$15,87 \%$

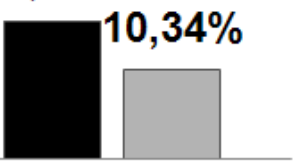

Outros

FIGURA 4. Formas de uso das plantas medicinais entre os informantes do Sítio Nazaré, município de Milagres-CE.

informantes relataram que na ausência de remédios convencionais, encontram como alternativa imediata, à espécie Croton grewioides (canelinha de cheiro), para amenizar os sintomas considerados simples, como por exemplo, gripe e tosse, sem contar que eles a utilizam como uma bebida quente, na falta do pó de café no período da tarde.

O interesse de repassar o conhecimento sobre as plantas que fazem bem à saúde para as gerações seguintes foi retratado pela comunidade estudada, assim como, a interação com o meio ambiente, em busca de prover meios de sobrevivência.

Durante a realização deste trabalho, observou-se que, apesar da comunidade do Sítio Nazaré estar inserida em uma área de fácil acesso, ter a implantação de um Posto de Saúde, localizado próximo à sede do município de Milagres-CE, muitas pessoas ainda mantêm a forma tradicional de curar suas enfermidades, através das plantas medicinais.

A partir de pesquisas com plantas medicinais, tendo como referência comunidades rurais, o pesquisador, acaba sendo de certa forma, um norteador, o qual pode e deve planejar caminhos que orientem no manejo da vegetação e conservação das espécies ocorrentes na área estudada, tendo em vista, que a Caatinga que tem as suas particularidades relevantes para a comunidade local. Desta forma, oferece-se uma importante contribuição, afim de que surjam outras pesquisas para ampliar o conhecimento do bioma, especialmente no que se refere à exploração racional dos seus recursos naturais.

\section{AGRADECIMENTO}

À comunidade do Sítio Nazaré pela receptividade e disponibilidade durante os trabalhos de campo e pelos momentos de aprendizado. Ao senhor Fernando Tavares, proprietário da Reserva Legal, pela permissão e contribuição nesta pesquisa. À CAPES pela concessão de bolsa para realização deste trabalho. 


\section{REFERÊNCIAS}

ALBUQUERQUE, U. P. Introdução à etnobotânica. 2. ed. Rio de Janeiro: Editora Interciência, 2005. 93p.

ALBUQUERQUE, U.P.; ANDRADE, L.H.C. Uso de recursos vegetais da Caatinga: o caso do agreste do estado de Pernambuco (Nordeste do Brasil). Interciência, v.27, n.7, p.336-46, 2002.

ALBUQUERQUE, U.P.; LUCENA, R.F.P. Métodos e técnicas de pesquisa etnobotânica. Recife: Livro Rápido/ NUPEEA, 2004. 189p.

BAILEY, K. Methods of social research. 4.ed. New York: The Free Press, 1994. 588p.

BALDAUF, C. et al. "Ferveu, queimou o ser da erva": conhecimentos de especialistas locais sobre plantas medicinais na região Sul do Brasil. Revista Brasileira de Plantas Medicinais, Botucatu, v.11, n.3, p.282-291, 2009.

BRIDSON, D.; FORMAN, L. The herbarium handbook. Kew: The Royal Botanic Gardens, 1998. 732p.

CASTRO, A. A. J. F. Florística e fitossociologia de um cerrado marginal brasileiro, Parque Estadual de Vassununga, Santa Rita do Passa Quatro- SP. 1987. 240p. Dissertação (Mestrado- Área de Concentração em Ciências Biológicas), Departamento de Biologia, Universidade Estadual de Campinas, Campinas.

FLORENTINO, A.T.N.; ARAÚJO, E.L.; ALBUQUERQUE,U.P. Contribuição de quintais agroflorestais na conservação de plantas da caatinga, município de Caruaru, PE, Brasil. Acta Botanica Brasilica, v.21, n.1, p.37-47, 2007.

FORZZA, R.C. et al. Lista de Espécies da Flora do Brasil. Jardim Botânico do Rio de Janeiro, 2012. Disponível em:< http://floradobrasil.jbrj.gov.br/2012/>. Acesso em: 10 abr. 2012.

IBGE. Instituto Brasileiro de Geografia e Estatística. Cidades@ 2010. Disponível em:<http://www.ibge.gov. br/cidadesat/link.php?uf=ce>. Acesso em: 20 ago. 2010.

IPECE. Instituto de Pesquisa e Estratégia Econômica do Ceará. Perfil Básico Municipal: Milagres. Fortaleza, 2009. Disponível em:<http://www.ipece.ce.gov.br/ publicacoes/perfil_basico/pbm-2009/Milagres_Br_ office.pdf>. Acesso em: 03 ago. 2010.

MACIEL, M.A.M. et al. Plantas medicinais: a necessidade de estudos multidisciplinares. Revista Química Nova, v. 23, n. 3, p. 429-438. 2002.

MATOS, F.J. de A. Introdução à fitoquímica experimental. Fortaleza: Editora UFC, p.44-45. 1997.

MARINHO, M.G.V. Levantamento de plantas medicinais em duas comunidades do Sertão Paraibano, Nordeste do Brasil, com ênfase na atividade Imunológica de Amburana cearensis (F. All.) A. C. Smith (Fabaceae). 2006.171p. Tese (Doutorado - Área de Concentração em Farmacologia), Departamento de Farmácia, Universidade Federal da Paraíba, João Pessoa.

MARINHO, M.G.V. et al. Levantamento etnobotânico de plantas medicinais em área de caatinga no município de São José de Espinharas, Paraíba, Brasil. Revista Brasileira de Plantas Medicinais, Botucatu, v.13, n.2, p.170-182, 2011.

MARTINS, F. R. O método de quadrantes e a fitossociologia de uma floresta residual no interior do Estado de São Paulo: Parque Estadual de Vassununga. 1979. 239p. Tese (Doutorado- Área de Concentração em Ciências), Departamento de Biociências, Universidade de São Paulo, São Paulo.

OLIVEIRA, R.L.C. et al. Tópicos em conservação, etnobotânica e etnofarmacológica de plantas medicinais. Recife: NUPEEA/ Sociedade Brasileira de Etnobiologia e Etnoecologia. p. 165-88. 2005.

PILLA, M.A.C. et al. Obtenção e uso de plantas medicinais no distrito de Martim Francisco, Município de Mogi Mirim, SP, Brasil. Acta Botanica Brasilica, v.20, n.4, p.789-802. 2006. Disponível em:<http://www.ibb.unesp. $\mathrm{br} /$ servicos/publicacoes/rbpm/pdf_v12_n1_2010/ v12_n01_31_42.pdf>. Acesso em: 07 mar. 2011.

RODĀL, M.J.N. et al. Manual sobre métodos de estudo florístico e fitossociológico - ecossistema caatinga. Brasília: Sociedade Botânica do Brasil/Seção Regional de Pernambuco. 32p. 1992.

SANTOS, M.R.A. et al. Uso de plantas medicinais pela população de Ariquemes, em Rondônia. Horticultura Brasileira, v. 26, p. 244-250. 2008.

SILVA, W.A. et al. Levantamento etnobotânico de plantas medicinais na cidade de São João da Ponte-MG. Revista de Biologia e Farmácia-BioFar, v. 7, n 1, p. 122-131, 2012. 